\title{
Crystallography Of Modular Materials
}

\author{
GIOVANNI FERRARIS \\ Department of Mineralogical and Petrologic Sciences \\ University of Turin \\ EMIL MAKOVICKY \\ Mineralogical Department of the Geological Institute \\ University of Copenhagen \\ STEFANO MERLINO \\ Department of Earth Science \\ University of Pisa
}




\section{Contents}

1 Modular series-Principles and types 1

1.1 Brief outline 2

1.2 Hierarchical classification of structures 3

1.3 Short recapitulation of non-modular categories of similarity 5

1.4 Elements of modular description. Types of homologous/
polysomatic series

1.5 Polysomatism $\quad 35$

1.6 Chemical composition series 41

Variable-fit homologous series and series with a combined
character

1.8 Merotype and plesiotype series 57

1.9 Ordered derivatives of solid solutions as modular structures $\quad 110$

1.10 Principles of prediction of modular structures 113

2 OD structures 127

$\begin{array}{lll}2.1 & \text { Introduction } & 127\end{array}$

$\begin{array}{ll}2.2 & \text { OD character of wollastonite } \\ 2.328\end{array}$

$\begin{array}{ll}2.3 & \text { OD structures of equivalent layers } \\ 2.433\end{array}$

2.4 Examples of $O D$ families built up with equivalent layers $\quad 154$

2.5 OD structures built up with $M>I$ kinds of layers $\quad 180$

2.6 Examples of OD structures consisting of two kinds of layers $\quad 190$

2.7 List of other OD structures 201

$\begin{aligned} & \text { Appendix } 2.1 \text { Table of monoclinic and orthorhombic OD-groupoid } \\ & \text { families }\end{aligned}$
202

Appendix 2.2 Diffraction effects in wollastonite 204

3 Polytypes and polytype categories $\quad 207$

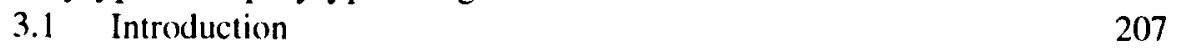

4 Application of modularity to structure description and modelling 227

$\begin{array}{lll}4.1 & \text { Introduction } & 227\end{array}$

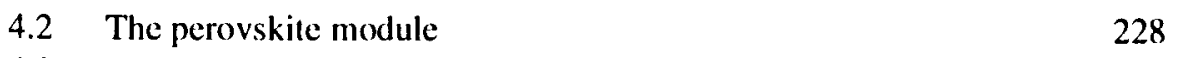

4.3 Structures based on spinel modules 244

4.4 Slicing tetrahedral and octahedral layers 250

4.5 Miscellaneous modular structures $\quad 269$

$\begin{array}{lll}4.6 & \text { Some conclusions } & 278\end{array}$ 
5 Modularity at crystal scale - Twinning

5.1 Classification of twins

5.2 Consequences of twinning

5.3 Detwinning procedure

5.4 Examples

5.5 Conclusions

References

309

Subject Index 